\title{
Comparison of Mechanical Properties of Ni[sub]3Al Thin Films in Disordered FCC and Ordered L1[sub]2 Phases
}

\section{Citation}

Huang, Yucong, Michael J. Aziz, John W. Hutchinson, Anthony G. Evans, R. Saha, and William D. Nix. 2001. Comparison of Mechanical Properties of Ni[sub]3Al Thin Films in Disordered FCC and Ordered L1[sub]2 Phases. Acta materialia 49(14): 2853-2861.

\section{Published Version}

http://dx.doi.org/10.1016/S1359-6454(01)00094-5

\section{Permanent link}

http://nrs.harvard.edu/urn-3:HUL.InstRepos:2797290

\section{Terms of Use}

This article was downloaded from Harvard University's DASH repository, and is made available under the terms and conditions applicable to Other Posted Material, as set forth at http:// nrs.harvard.edu/urn-3:HUL.InstRepos:dash.current.terms-of-use\#LAA

\section{Share Your Story}

The Harvard community has made this article openly available.

Please share how this access benefits you. Submit a story.

\section{Accessibility}




\title{
Comparison of Mechanical Properties of $\mathrm{Ni}_{3} \mathrm{Al}$ Thin Films in Disordered FCC and Ordered $\mathrm{L1}_{2}$ Phases
}

\author{
Y. HUANG, M. J. AZIZ, J. W. HUTCHINSON, and A.G. EVANS* \\ Division of Engineering and Applied Sciences, Harvard University, Cambridge, MA 02138 \\ R. SAHA, W. D. NIX \\ Dept. of Materials Science and Engineering, Stanford University, Stanford, CA 24305
}

\begin{abstract}
We report the results of several experiments isolating the effect of long-range order on mechanical properties of intermetallic compounds. Kinetically disordered $\mathrm{FCC} \mathrm{Ni}_{3} \mathrm{Al}$ (Ni 76\%) thin films were produced by rapid solidification following pulsed laser melting. For comparison, compositionally and microstructurally identical films with ordered $\mathrm{L}_{2}$ structure were produced by subsequent annealing at $550{ }^{\circ} \mathrm{C}$ for 2 hours. These FCC and $\mathrm{L1}_{2} \mathrm{Ni}_{3} \mathrm{Al}$ thin films were tested by nanoindentation for hardness and Young's modulus, and the critical strain to fracture was measured by straining the substrate under four-point bending. $\mathrm{Ni}_{3} \mathrm{Al}$ thin films in the disordered phase were found to have nearly twice the critical strain to fracture, more than three times the fracture toughness, and about $20 \%$ lower hardness than in the ordered counterpart. Blunter crack tips and crack bridging observed in the disordered phase also illustrate increased ductility. The increased plasticity of $\mathrm{Ni}_{3} \mathrm{Al}$ due to chemical disorder is manifested both within the grains and at the grain boundaries. Young's moduli of the ordered and disordered materials were found to be indistinguishable.

Keywords: rapid solidification; intermetallic compounds; hardness testing; toughness; order-disorder phenomena
\end{abstract}

\section{INTRODUCTION}

Ordered intermetallic compounds are generally brittle at ambient temperature, whereas chemically disordered alloys tend to be more ductile. While ductile as a single crystal, the equilibrium ordered $\mathrm{L}_{2}\left(\gamma^{\prime}\right)$ phase of stoichiometric intermetallic compound $\mathrm{Ni}_{3} \mathrm{Al}$ is brittle in its polycrystalline form in ambient environment [Liu and Stiegler, 1984]. However, when the availability of atomic $\mathrm{H}$ is carefully limited, e.g. by testing under ultrahigh vacuum with the ion gauge off, polycrystalline $\mathrm{Ni}_{3} \mathrm{Al}$ is found to be intrinsically ductile, with tensile elongations exceeding $40 \%$ and predominantly $(>70 \%)$ transgranular fracture [Cohron et al., 1996]. While environmental effects play a very important role in the embrittlement of $\mathrm{Ll}_{2}$ intermetallic compounds, it has also been proposed that chemical order can embrittle grain boundaries by inhibiting dislocation transmission through the boundaries [King et al., 1991] and by weakening the grain boundaries through the production of atomic size cavities in grain boundaries [Vitek and Chen, 1991]. A recent review on the subject was given by Yoo and $\mathrm{Fu}$ [1998]. In addition, it is possible that the ordered structure at grain boundaries plays a role in $\mathrm{H}$ embrittlement.

Disorder-induced ductility enhancement has been observed in FeCo [Zhao et al., 1993], an ordered alloy exhibiting a wide single-phase field and a weak ordering energy, in the presence of sulfur at the grain boundaries. An assessment of the effect of chemical 
order on ductility is now possible for $\mathrm{Ni}_{3} \mathrm{Al}$ using pulsed laser melting induced rapid solidification. This technique can produce kinetically disordered intermetallics [West and Aziz, 1991] even for phases such as $\mathrm{Ni}_{3} \mathrm{Al}$ with such high ordering energies that in equilibrium they are chemically ordered all the way to the melting point [Cahn et al., 1987]. Using this technique we produced kinetically disordered $\mathrm{FCC} \mathrm{Ni} 3 \mathrm{Al}(\mathrm{Ni} 76 \%$ ) thin films. For comparison, compositionally and microstructurally identical films with the ordered $\mathrm{Ll}_{2}$ structure were produced by subsequent low-temperature annealing.

Here we report the result of a study to assess the effect of ordering on mechanical properties. The hardness and Young's modulus of the FCC and $\mathrm{L}_{2} \mathrm{Ni}_{3} \mathrm{Al}$ thin films were tested by nanoindentation. The critical strain to fracture was measured by applying strain to the substrate under four-point bending combined with a measurement of the residual strain in the thin film by substrate curvature measurement. The ratio of the fracture toughness of the $\mathrm{FCC}$ and $\mathrm{L}_{2}$ phases was derived from measured ratios of the critical strains to fracture and Young's moduli.

\section{EXPERIMENTAL PROCEDURE}

\subsection{Production of Compositionally and Microstructurally Identical Disordered and Ordered Thin Films}

$\mathrm{Ni}_{76} \mathrm{Al}_{24}$ films $170 \mathrm{~nm}$ and $300 \mathrm{~nm}$ thick were produced by electron-beam coevaporation of separate nickel (99.9\%) and aluminum $(99.99 \%)$ sources onto silicon wafers covered with $200 \mathrm{~nm}$ and $1 \mu \mathrm{m}$ thermal oxide. Oxidized silicon wafers were chosen because they were suitable for subsequent laser disordering and sample fabrication processing due to their optical flatness, well-characterized thermal properties and processibility by chemical etchants. To promote film adhesion, $12 \mathrm{~nm}$ of $\mathrm{Cr}$ was first deposited and the wafer substrates were sputter cleaned with $\mathrm{Ar}^{+}$ions before and during the first few monolayers of $\mathrm{Cr}$ deposition; a vacuum break and $\mathrm{Ar}^{+}$sputtering also preceded deposition of the $\mathrm{Ni}_{3} \mathrm{Al}$. The composition of the thin film was determined by Rutherford Backscattering Spectrometry (RBS), with an uncertainty of $0.5 \%$. The samples were irradiated by a spatially homogenized $\mathrm{XeCl}^{+}$excimer laser pulse of $308 \mathrm{~nm}$ with a temporal duration of $30 \mathrm{~ns}$ FWHM (Fig. 1). The thin films were fully melted and solidified with a very high velocity in the range of several meters per second [West and Aziz, 1991]. When the velocity of the solidification front exceeds a critical value, disorder trapping [Boettinger and Aziz, 1989] goes to completion and the formation of the metastable disordered phase occurs. To produce compositionally and microstructurally identical ordered $\mathrm{L}_{2}$ samples, these kinetically disordered FCC samples were subsequently annealed at $550{ }^{\circ} \mathrm{C}$ for 2 hours. The micrographs (Fig. 2) taken by Scanning Electron Microscopy (SEM) demonstrate that the grain sizes for the $\mathrm{FCC}$ and $\mathrm{L1}_{2}$ phases are similar, with a distribution from 0.5 to $1.5 \mu \mathrm{m}$. There was no observable grain growth during the reordering anneal.

Phase identification was performed by X-ray diffraction with a GE $\vartheta-2 \vartheta$ diffractometer using $\mathrm{K}_{\alpha}$ radiation from a $\mathrm{Cr}$ anode $\mathrm{X}$-ray tube. The $\mathrm{FCC}$ and $\mathrm{L}_{2}$ phases can be distinguished by monitoring a superlattice and fundamental reflection pair with parallel scattering vectors (e.g., 110 and 220). By monitoring the reflections resulting from the same scattering crystal planes, we ensured that the reflection pair comes from the same grains, thereby eliminating the possibility of a texturing artifact. Fig. 3 shows typical 
results. After laser melting, the $110 \mathrm{Ll}_{2}$ superlattice peak vanished but the $220 \mathrm{FCC}$ fundamental peak was still present, demonstrating the formation of the metastable FCC phase. After the furnace anneal, both the $\mathrm{L}_{2}$ superlattice peak and the $\mathrm{FCC}$ fundamental peak were present. In order to limit grain growth and grain boundary segregation the annealing time was restricted to 2 hours, rather than the 24 hours used in an earlier kinetic study [West and Aziz, 1991]. Therefore the annealed samples may not be fully ordered.

\subsection{Determination of Hardness and Young's Modulus by Nanoindentation}

Depth-sensing indentation tests were performed using a Nanoindenter with a Berkovich diamond tip on $170 \mathrm{~nm}$ and $300 \mathrm{~nm}$ thick $\mathrm{FCC}$ and $\mathrm{L}_{2} \mathrm{Ni}_{3} \mathrm{Al}$ films on oxidized silicon substrates with $1 \mu \mathrm{m}$ thermal oxide. Fig. 4 is a typical load / displacement curve for nanoindentation. Indentations were conducted at various locations on each kind of thin film, with each indentation having loading and unloading cycles at three increasing indentation depth intervals. Data were obtained for each at six indentation depth intervals up to a depth of $160 \mathrm{~nm}$ at ten different locations. Young's modulus and hardness were determined by using a comprehensive procedure developed by Oliver and Pharr [1992], which was extended based on the works of Doerner and Nix [1986].

\subsection{Fabrication of Tensile Test Specimen}

To measure the critical strain to fracture of the thin films though substrate deformation, the thin films need to be transferred from oxidized silicon substrates, which were suitable only for laser disordering, to more ductile substrates, such as stainless steel beams. Because $\mathrm{Ni}_{3} \mathrm{Al}$ films were under biaxial tension after laser melting, to prevent them from peeling off during the transfer process a $120 \mathrm{~nm}$ thick layer of $\mathrm{Ni}$ in biaxial compression was formed by sputter deposition onto the $\mathrm{Ni}_{3} \mathrm{Al}$ films. The metal bilayer was then patterned into a series of $175 \mu \mathrm{m}$ thin lines, allowing many of them to be tested at the same time in a single "sample". One FCC and one $\mathrm{L}_{2}$ sample, with dimensions $6 \mathrm{~mm} \times$ $5 \mathrm{~mm}$, were placed next to each other and attached to a $6 \mathrm{~mm} \times 3 \mathrm{~mm} \times 60 \mathrm{~mm}$ stainless steel beam using 10 to $20 \mu \mathrm{m}$ of epoxy, with the metal films facing the epoxy. After the oxidized silicon substrate was mechanically thinned, the specimen was covered with an etch-resistant layer of beeswax. A $4 \mathrm{~mm} \times 3 \mathrm{~mm}$ window was opened on the back of each sample's etch-resistant layer, allowing the remaining silicon and oxide to be etched away using acid and base solutions, exposing the central length of the underlying metal lines. The $1 \mathrm{~mm}$ silicon frame surrounding the metal lines was needed to protect the metal thin films in the etching process, and the frame did not interfere with mechanical testing. After the removal of the oxide, the newly-exposed $\mathrm{Cr}$ adhesion layer was also removed by etching. The $170 \mathrm{~nm} \mathrm{Ni}_{3} \mathrm{Al}$ films were successfully transferred with the Ni supportive layer; however, the $300 \mathrm{~nm}$ films peeled off.

The final configuration of the sample is shown in Fig. 5. Ordered and disordered thin film samples, patterned into thin lines of $175 \mu \mathrm{m}$ wide and more than $2 \mathrm{~mm}$ long, were placed side by side on a stainless steel beam, with each sample normally consisting of more than ten lines. Each line consisted of a $170 \mathrm{~nm}$ thick $\mathrm{Ni}_{3} \mathrm{Al}$ layer and a $120 \mathrm{~nm}$ thick Ni layer underneath, followed by 10 to 20 um thick of epoxy attaching them to the stainless steel beam. 


\subsection{Determination of Critical Strain to Fracture}

The experimental setup is also shown in Fig. 5. The fracturing of the metal lines was observed in real time through a microscope and recorded by video, and the applied strain was recorded by a strain gage attached to the stainless steel beam on the opposite side of the metal thin films. Tests confirmed that within the range of the experiment, the readings from strain gages attached to both sides of the beam agreed very well with each other. The applied strain to fracture was recorded as the strain gage reading at which the first crack appeared in each line.

The laser melting and rapid solidification process produced a large residual tensile stress in the films; the reordering anneal relaxed the tension somewhat. During the thin film transfer process, the strain state of the thin films away from the edges remains unchanged. Hence the strain of the thin film on the unstrained stainless steel beam can be obtained by measuring the strain of the film while it still sits on the oxidized silicon substrate, which was curved due to the film stress. The wafer curvature was measured by a scanning laser beam [Flinn et al., 1987] and the stress then can be calculated using Stoney's equation:

$$
\sigma_{\text {film }}=\left(\frac{Y_{\text {sub }} t_{\text {sub }}^{2}}{6 t_{\text {film }}}\right) K
$$

where $\sigma_{\text {film }}$ is the stress of the film, $Y_{\text {sub }}$ is the biaxial modulus of the substrate, $t_{\text {sub }}$ is the thickness of the substrate, $t_{\text {film }}$ is the thickness of the film, $K$ is the net curvature ( $1 /$ radius) change of the substrate due to the presence of the thin film, referred to the initial curvature of the thin film-free substrate. The elastic strains can be readily calculated given the biaxial moduli of the thin films.

The critical strain to fracture $\varepsilon_{\mathrm{c}}$ was obtained by combining the applied strain to fracture $\varepsilon_{\text {fract }}$ and the residual strain $\varepsilon_{\text {ini }}$ in the thin film:

$$
\varepsilon_{c}=\varepsilon_{\text {ini }}+\varepsilon_{\text {fract }} \text {. }
$$

Additionally, the shape and bluntness of the crack tips in the FCC and $\mathrm{L1}_{2}$ films were examined and compared using SEM, to provide additional qualitative evidence of the relative ductility of the two phases.

\section{$3 \quad$ Results and Discussion}

\subsection{Hardness and Elastic Modulus}

The hardness results of the nanoindentation tests are shown in Fig. 6. At all indentation depths the disordered FCC film is less hard than its ordered $\mathrm{L}_{2}$ counterpart. Because the $1 \mu \mathrm{m} \mathrm{SiO}_{2}$ underneath the metal film has a hardness of about $10 \mathrm{GPa}$, which is higher than that of the metal films, as the indentation depth increased beyond $40 \mathrm{~nm}$ the apparent hardness of the thin film also increased due to the increasing influence of the $\mathrm{SiO}_{2}$. The measured hardness of the $170 \mathrm{~nm}$ film was higher than that of the $300 \mathrm{~nm}$ film of the same phase at the same depth, at least in part because the thinner film is more susceptible to the influence of the substrate. At an indentation depth smaller than $40 \mathrm{~nm}$, the calculated values of the hardness of the films were rising with increasing depth. The values for bulk fused silica, which served as a calibration, exhibited the same behavior. 
This artifact is attributed to the difficulty of determining the shape of the nanoindenter tip at very shallow depth. Despite the limitations, the hardness data clearly demonstrated the reduction in hardness upon disordering.

The results of the Young's modulus measurement are shown in Fig. 7. Because elastic effects have a longer range than plastic effects, the influence of the substrate is more significant in the measurement of Young's modulus than in the hardness measurement. The underlying $\mathrm{SiO}_{2}$ has a Young's modulus of less than $80 \mathrm{GPa}$, which is lower than that of $\mathrm{Ni}_{3} \mathrm{Al}$. Therefore, as the indentation depth increased, the apparent Young's modulus dropped, moving further away from the bulk value of $178 \mathrm{GPa}$ and toward that of the underlying silicon dioxide. It is probable that even with a $40 \mathrm{~nm}$ indentation depth, which is only $13 \%$ of the thickness of the $300 \mathrm{~nm}$ film, the influence of the substrate could already be felt [Tsui and Pfarr, 1999]. However, the deviations of the thin film Young's modulus from the bulk value at depths of $20 \mathrm{~nm}$ and below might be due to the limitations of the instrument. The observation that the apparent Young's modulus of the $170 \mathrm{~nm}$ thin film had a larger deviation from the bulk value than did that of the $300 \mathrm{~nm}$ thin film of the same phase at the same indentation depth is consistent with the increased susceptibility of thinner films to substrate influences. Despite these qualifications it is still clear that within the error of the experiment, there is no observable difference in elastic modulus between the two kinds of films.

\subsection{Critical Strain to Fracture}

The measured strain to fracture is shown in Fig. 8(a). Real time microscopy during four-point bending tests showed that, despite the higher residual elastic strain (discussed below), the externally applied strain to fracture of the FCC films was significantly higher than that of the $\mathrm{L}_{2}$ films. It was observed under the microscope that after the first crack appeared on any particular metal line within a sample, cracks appeared on all of the lines of the same sample within an additional strain of $0.1 \%$. Therefore $0.1 \%$ strain was taken as the upper bound of the error of the measurement of applied fracture strain.

We were able to obtain, with the substrate curvature measurement, the residual strain $\varepsilon_{\text {ini }}$ of only one ordered sample and one disordered sample. The residual tensile stress of the disordered thin films was about $2.2 \mathrm{GPa}$, indicating a strain of $0.8 \%$. The residual stress of reordered thin films was about $1.6 \mathrm{GPa}$, indicating a strain of $0.6 \%$. The critical strain to fracture, calculated according to Eq. (2), is shown in Fig. 8(b). Ignoring any possible additional contribution from sample to sample deviation in residual strain, the critical strain of the FCC film is about 1.8 times that of the ordered $\mathrm{L}_{2}$ counterpart, with a standard deviation of $30 \%$.

\subsection{Effect of Epoxy layer and Ni protective Layer on Measured Strain to Fracture}

The epoxy thickness was found to vary from 10 to $20 \mu \mathrm{m}$ from sample to sample. Because they were more than thirty times thicker than the metal bilayers, the epoxy layers can be considered to be infinitely thick for the analysis of the energetics of crack propagation across the metal lines. This assumption is supported by the experimental result that despite a likely variation of epoxy thickness from sample to sample, the measured values of strain to fracture for different samples of each phase were quite similar.

Sample charging during SEM examination after the bending test suggested that the cracks went through not only the $170 \mathrm{~nm}$ thick $\mathrm{Ni}_{3} \mathrm{Al}$ layer, but also the underlying $120 \mathrm{~nm}$ 
thick Ni supporting layer, exposing bare epoxy. However, additional four-point bending tests on $170 \mathrm{~nm} \mathrm{Ni} 3 \mathrm{Al}$ with varying $\mathrm{Ni}$ supporting layer thickness showed no sensitivity of the measured fracture strain to the supporting layer thickness over the range from 20 to 180 $\mathrm{nm}$. Our interpretation of this result is that because $\mathrm{Ni}_{3} \mathrm{Al}$ is much more brittle than $\mathrm{Ni}$, the fracture strain of the bilayer is determined by the fracture strain of $\mathrm{Ni}_{3} \mathrm{Al}$. Due to the huge elastic mismatch between the $\mathrm{Ni}$ and epoxy, once the top $\mathrm{Ni}_{3} \mathrm{Al}$ layer cracked open, the critical strain to fracture of the Ni right underneath the crack would be dramatically reduced. Therefore, it is likely that the $\mathrm{Ni}_{3} \mathrm{Al}$ layer cracked first and then the underlying $\mathrm{Ni}$ layer followed.

\subsection{Fracture Toughness}

If the $\mathrm{Ni}_{3} \mathrm{Al}$ thin film indeed fractured first, then the Ni layer can be treated as part of the substrate and a quantitative comparison of the fracture toughness of the two $\mathrm{Ni}_{3} \mathrm{Al}$ phases can be made. If, however, our interpretation turns out to be incorrect, and some unanticipated effect causes the insensitivity of the measured fracture strain to Ni thickness, then the following analysis can be taken only as a qualitative indication of the higher fracture toughness of the disordered $\mathrm{Ni}_{3} \mathrm{Al}$ films.

The cracking mechanism of thin brittle films on ductile substrates has been well established [Evans et al. 1988, Hutchinson and Suo 1992, Beuth and Klingbell 1996]. Film cracking is governed by steady state crack growth across the film, normally initiated from defects at the edges. The fracture toughness of an elastic thin film on an elastic substrate is given by

$$
\Gamma \approx \frac{1}{2} \varepsilon_{c}^{2} h Y g
$$

where $\varepsilon_{c}$ is the critical strain to fracture of the film, $h$ is the thickness of the film, $Y$ is the biaxial modulus of the film, and $g$ is a function of elastic mismatch between film and substrate, which effectively included the $120 \mathrm{~nm}$ thick Ni layer and the effectively semiinfinite epoxy layer.

Assuming the deformation of the $\mathrm{Ni}_{3} \mathrm{Al}$ layer and $\mathrm{Ni}$ layer is predominantly elastic, the ratio of the fracture toughness of the two $\mathrm{Ni}_{3} \mathrm{Al}$ phases is then given by:

$$
\frac{\Gamma^{\text {disord }}}{\Gamma^{\text {ord }}}=\left(\frac{\varepsilon_{c}}{\varepsilon_{c}^{\prime}}\right)^{2}\left(\frac{h}{h^{\prime}}\right)\left(\frac{Y}{Y^{\prime}}\right)\left(\frac{g}{g^{\prime}}\right)
$$

where the prime identifies the ordered phase. The thickness of the ordered and disordered films were the same. There was no observable difference between the Young's moduli, as found by the nanoindentation test. Because the supportive Ni layers were the same for all films and epoxy layer was much thicker than the metal layers, the g factors should be the same for the ordered and disordered films. Therefore, all factors on the r.h.s. of Eq. (4) except the first factor are unity, and the ratio of the fracture toughness of the two phases reduces to:

$$
\frac{\Gamma}{\Gamma}=\left(\frac{\varepsilon_{c}}{\varepsilon_{c}^{\prime}}\right)^{2}
$$

As reported in the previous section, the ratio of critical strains of the two phases was measured to be $1.81 \pm 0.30$. Therefore the fracture toughness of the disordered FCC phase is approximately $3.2 \pm 0.60$ times that of the ordered $\mathrm{L1}_{2}$ phase. 


\subsection{SEM Examination of Crack Tip Morphology}

As shown by the plan-view micrograph (Fig. 9) taken by SEM, crack tip openings were sharp for the ordered phase and significantly blunter for the disordered phase, indicating that the disordered phase is more ductile [Shih, 1981]. Crack bridging is a source of crack resistance [He et al, 1997]. It was observed in the disordered films (Fig. 10), but not in the ordered films. These observations provide additional evidence of higher ductility of the disordered FCC phase.

\subsection{Discussion}

The nano-indentation hardness of the FCC film is less than that of the $\mathrm{L}_{2}$ film even at indentation depths below $40 \mathrm{~nm}$, which is about $5 \%$ of the average grain size and $13 \%$ of the $300 \mathrm{~nm}$ film thickness. This result indicates that plasticity within a grain is enhanced through disordering. This is not surprising because less driving force would be required to move a dislocation in the FCC than in the $\mathrm{L}_{2}$ structure. However, because $\mathrm{L}_{2}$ $\mathrm{Ni}_{3} \mathrm{Al}$ fractures at grain boundaries, the increased strain to fracture is indicative of a boundary strengthening process. Although plasticity within the grains might affect the strain to fracture via localized plastic dissipation, such an effect seems very unlikely to be able to account for the doubling of the critical fracture strain observed here. Hence strengthening at the grain boundary must be also enhanced by disordering, either through direct grain boundary strengthening or through facilitating mechanisms associated with dislocations at grain boundaries.

Impurity segregation to the grain boundary during the reordering anneal could be a concern. The oxidized silicon substrates of two $300 \mathrm{~nm} \mathrm{Ni}{ }_{3} \mathrm{Al}$ thin film samples -- one before and one after the reordering anneal -- were cleaved, and the fracture surfaces of the films were examined using a Physical Electronics Model 660 Scanning Auger Microprobe (SAM). The SAM has an electron beam size of $1 \mu \mathrm{m}$ and elemental sensitivity of $0.5 \%$ under the best of circumstances, but the small thin film fracture surface and charging from the $\mathrm{SiO}_{2}$ in the substrate may further degrade the sensitivity. The only strongly present impurity element was carbon, which is a contaminant commonly picked up while the samples are being transported to the SAM. There was at most just a trace amount of sulfur present on the fracture surfaces of both samples, and within the resolution of the SAM there was no difference between the two. Even if trace amounts of impurities, undetectable by SAM, segregated to the grain boundary during the reordering anneal and caused the reduction in fracture strength of the reordered films, such an effect cannot be responsible for the nano-indentation hardness results suggesting that disordered material is softer and more ductile than ordered material inside a grain.

Compared with bulk behavior, relatively high values of hardness and low values of the critical strain to fracture are to be expected in thin films. Thin films are known to have higher yield strength than bulk material due to smaller grain sizes, the formation of misfit dislocations at the film/substrate interface, and the interactions among dislocations confined to move in a thin film on a substrate. A recent review of these phenomena has been provided by Nix [1997]. Although we cannot extrapolate our thin film results to predict quantitatively the behavior of bulk materials, our results and interpretation imply that bulk $\mathrm{Ni}_{3} \mathrm{Al}$ should also be more ductile in the disordered FCC phase than in its microstructurally and compositionally identical $\mathrm{L}_{2}$ counterpart. 


\section{SUMMARY}

$\mathrm{Ni}_{3} \mathrm{Al}$ thin films were found to be more ductile in the disordered FCC phase than in the ordered $\mathrm{L}_{2}$ phase. The disordered FCC material exhibited nearly twice the critical strain to fracture, more than three times the fracture toughness, and about $20 \%$ lower hardness than its compositionally and microstructurally identical ordered $\mathrm{L}_{2}$ counterpart. The blunter crack tips and crack bridging observed in the disordered phase also illustrate its higher ductility. The increased plasticity of $\mathrm{FCC} \mathrm{Ni} 3 \mathrm{Al}_{\text {due }}$ to chemical disorder is manifested both inside the grain and across the grain boundary. Young's moduli of the ordered and disordered materials were found to be indistinguishable.

\section{ACKNOWLEDGEMENTS}

Research at Harvard was supported by NSF-DMR-97-27369 and NSF-DMR-9809363. We gratefully acknowledge technical assistance from D.E. Hoglund, F.N. Molea, E. Shaw, Y.Z. Lu, J.F. Chervinsky, J.A. Mullin, J.W. Kysar, D.R. Mumm, Y. Sugimura, and J.-S. Wang.

\section{REFERENCES}

*Present address: Princeton Materials Institute, Princeton University, Princeton NJ 08544.

1. C. T. Liu and J. O. Stiegler, Science, 1984, 226, 636.

2. J. W. Cohron, E. P. George, L. Heatherly, C. T. Liu and R. H. Zee, Intermetallics, 1996, 4, 497.

3. A. H. King, H. J. Frost, M. H. Yoo, Scr. Metall. Mater., 1991, 25, 1249.

4. V. Vitek and S. P. Chen, Scr. Metall. Mater., 1991, 25, 1237.

5. M. H. Yoo and C. L. Fu, Solid Sate Phenomena, 1998, 59-60, 273.

6. L. Zhao, I. Baker, and E. P. George, in High Temperature Ordered Intermetallic Alloys $V$., eds. I. Baker, R. Darolia, J.D. Whittenberger, and M.H. Yoo (Materials Research Society, Pittsburgh, 1993), p. 501.

7. J. A. West, J. T. Manos and M. J. Aziz, in High Temperature Ordered Intermetallic Alloys IV. , eds. L.A. Johnson, D.P. Pope, and J.O. Stiegler (Materials Research Society, Pittsburgh, 1991), p. 859.

8. R. W. Cahn, P. A. Siemers, J. E. Geijer and P. Bardhan, Acta Metall.,1987, 352737.

9. W. J. Boettinger and M. J. Aziz, Acta Metall., 1989, 37, 3379.

10. W. C. Oliver and G. M. Pharr, J. Mater. Res., 1992, 6, 1564.

11. M. F. Doerner and W. D. Nix, J. Mater. Res., 1986, 4, 601.

12. P. A. Flinn, D. S. Gardner and W. D. Nix, IEEE Transactions on Electronic Devices, 1987, ED-34, 689.

13. T.Y. Tsui and G.M. Pharr, J. Mater. Res, 1999,. 14, 292.

14. P. G. Sanders, V. K. Sikka, C. R. Howell and R. H. Baldwin, Scripta Met. et Mat., 1991, 25, 2365.

15. A. G. Evans, M. D. Drory and M.S. Hu, J. Mater. Res., 1988, 3, 1043.

16. J. W. Hutchinson and Z. Suo, Advances in Applied Mechanics, 1992, 29, 63.

17. J. L. Beuth and N. W. Klingbell, J. Mech. Phys. Solids, 1996, 44, 1411.

18. C. F. Shih, J. Mech. Phys. Solids, 1981, 29, 305.

19. M. Y. He, D. J. Wissuchek and A. G. Evans, Acta Mater., 1997, 45, 2813.

20. W.D. Nix, Materials Sci. Eng. A, 1997, 234-236, 37. 


\section{Excimer Laser (308 nm, 30ns)}
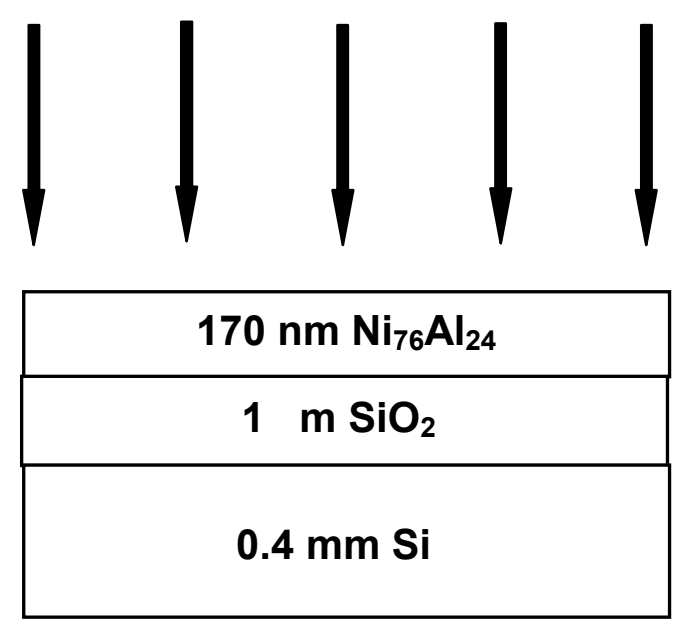

Figure 1. Thin film and laser configuration. 

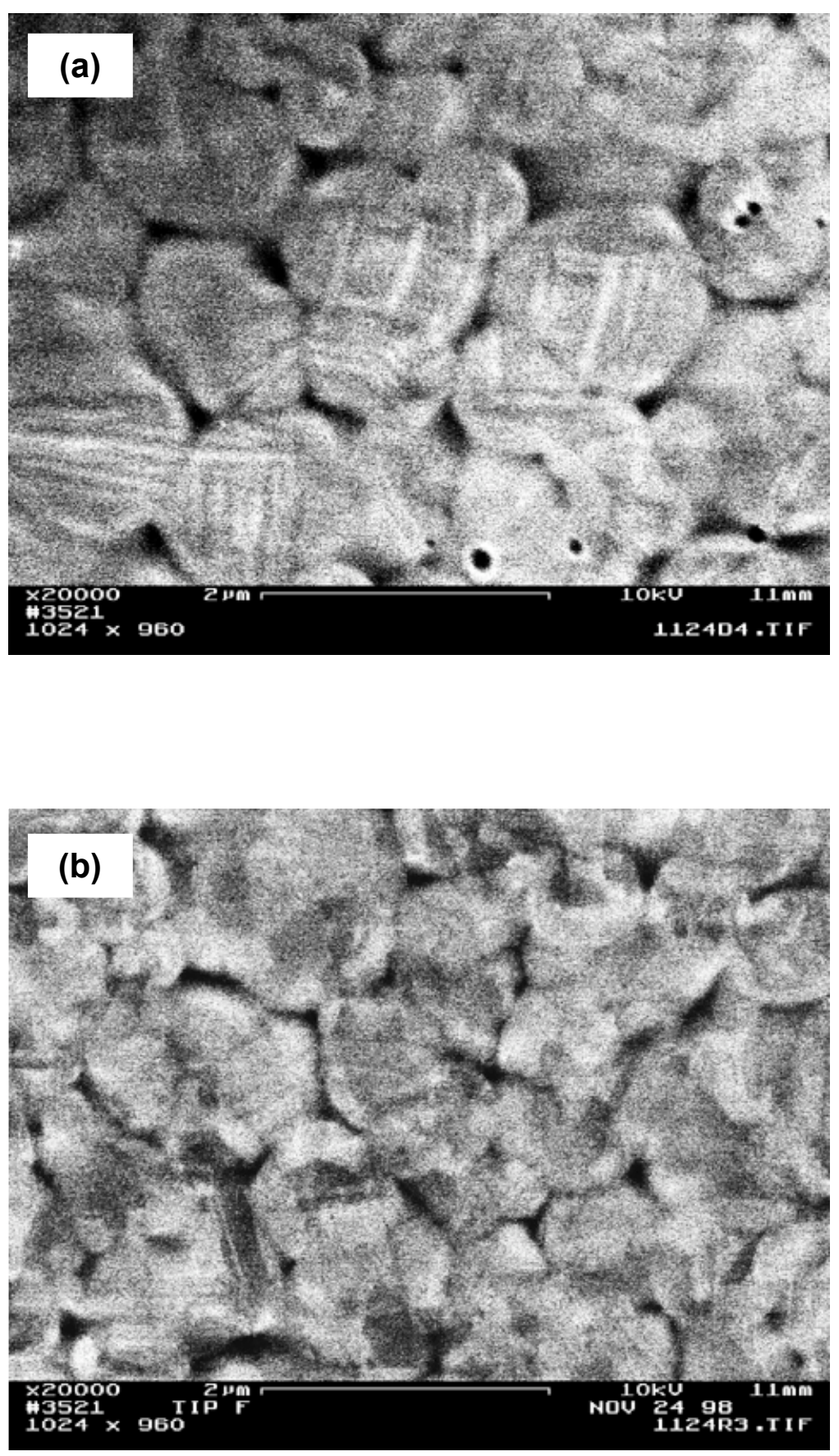

Figure 2. SEM micrograph of $\mathrm{Ni}_{3} \mathrm{Al}$ thin films. (a) After laser disordering, before furnace reordering. (b) After furnace reordering at $550{ }^{\circ} \mathrm{C}$ for 2 hours. No observable grain growth was observed. 

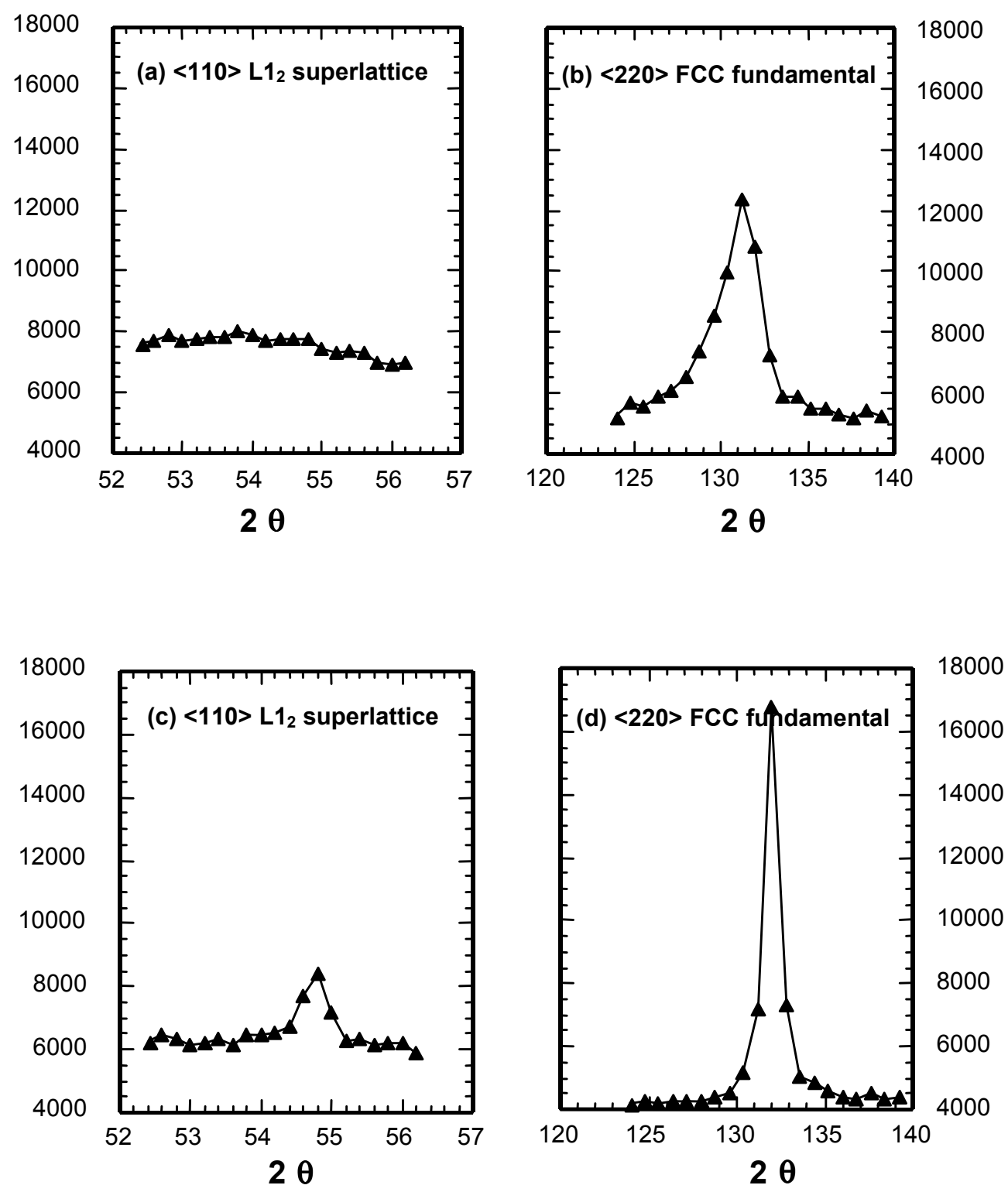

Figure 3. X-ray diffraction from kinetically disordered FCC (top) and subsequently annealed $\left(550{ }^{\circ} \mathrm{C}, 2 \mathrm{hr}\right.$.) $\mathrm{L}_{2}$ (bottom) material. 


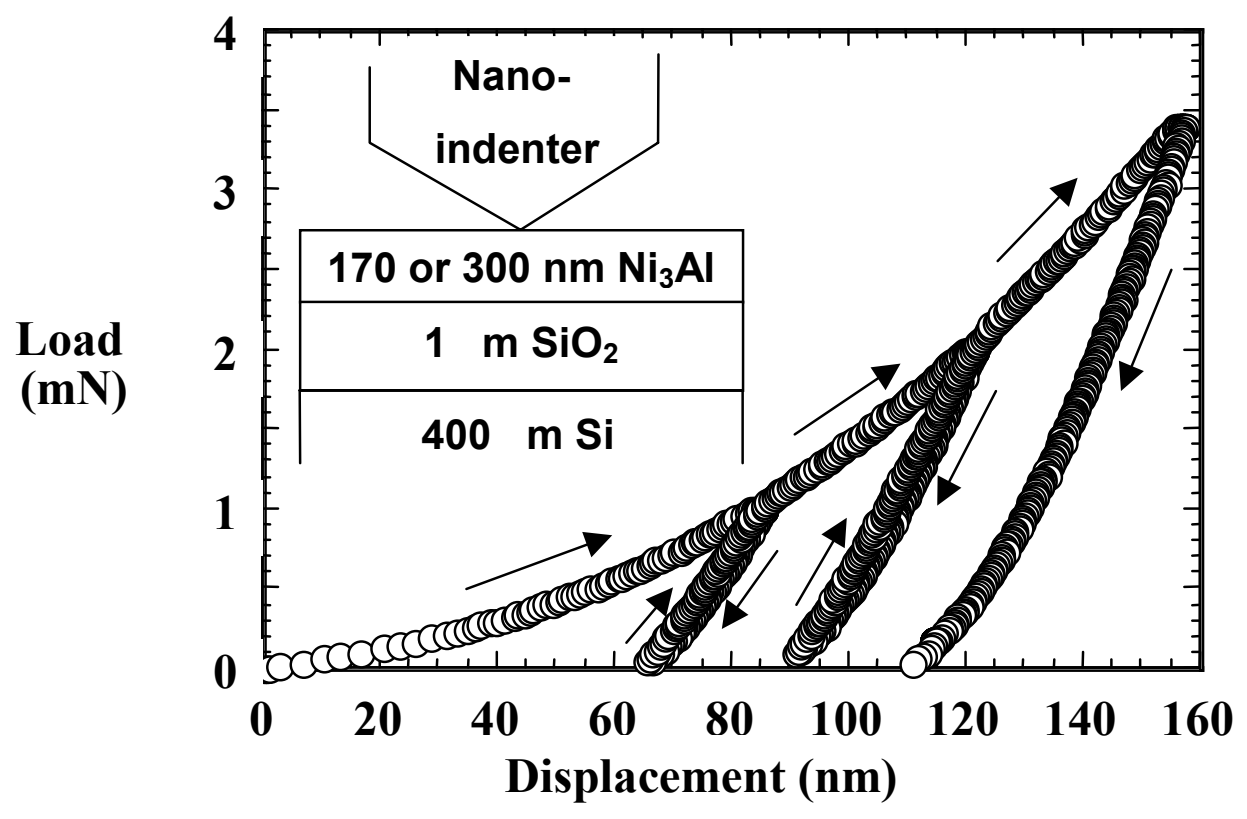

Figure 4. Typical loading and unloading curve of Nano-indentation test. 


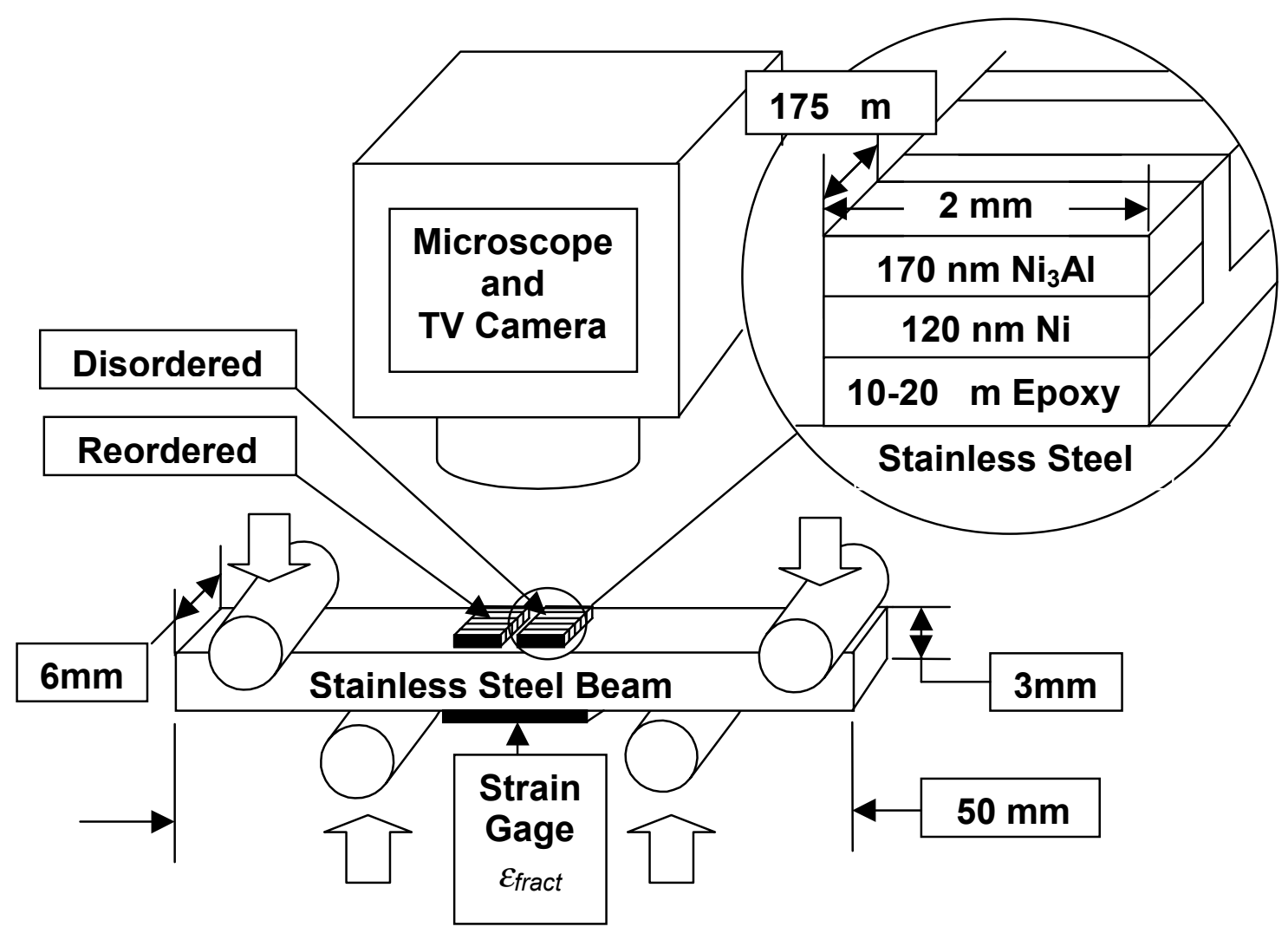

Figure 5. Experimental setup for real time microscopy with four-point bending test and final configuration of the test specimen. 


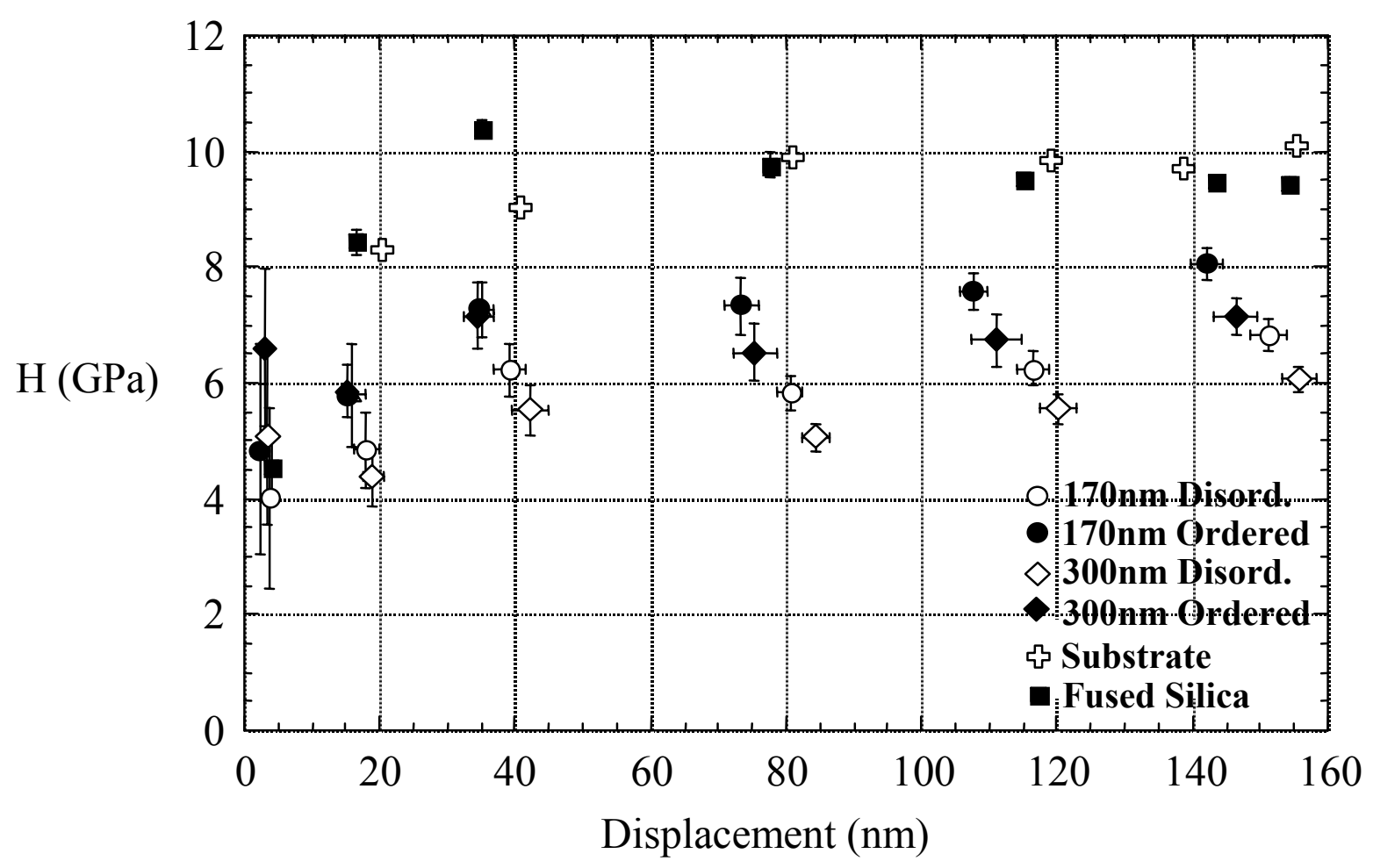

Fig 6. Hardness calculated from nano-indentation data of $\mathrm{Ni}_{3} \mathrm{Al}$ thin films with thickness $170 \mathrm{~nm}$ and $300 \mathrm{~nm}$, on oxidized silicon substrate with $1 \mu \mathrm{m} \mathrm{SiO}$. The ordered films have higher hardness than their disordered counterparts. Results for bare oxidized wafers and bulk fused silica are also shown. 


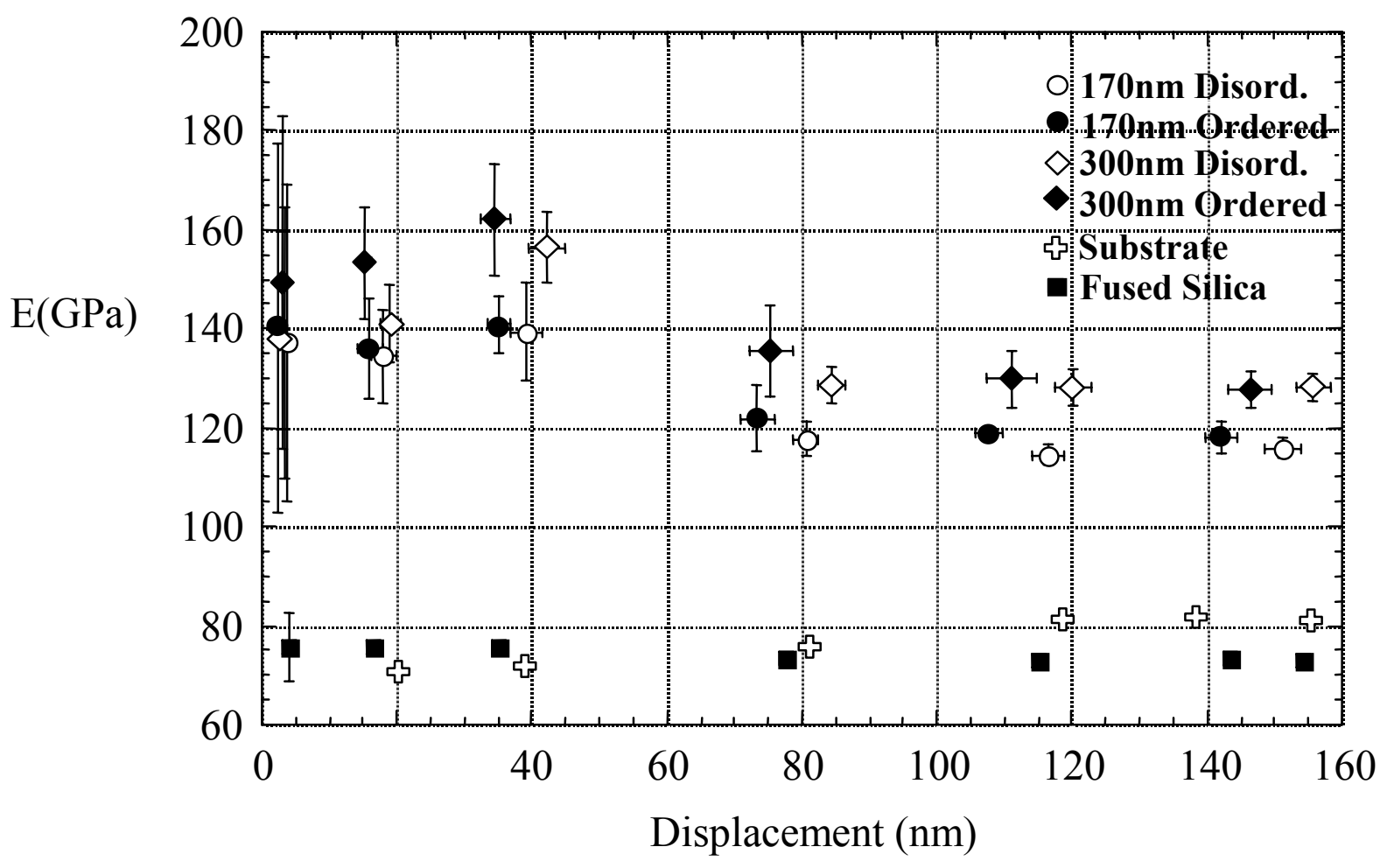

Fig 7. Young's Moduli calculated from nano-indentation data of $\mathrm{Ni}_{3} \mathrm{Al}$ thin films with thickness $170 \mathrm{~nm}$ and $300 \mathrm{~nm}$, on oxidized silicon substrate with 1 $\mu \mathrm{m} \mathrm{SiO}_{2}$. Within experimental error, there is no observable difference in Young's modulus between the ordered and disordered films. Results for bare oxidized wafers and bulk fused silica are also shown. 

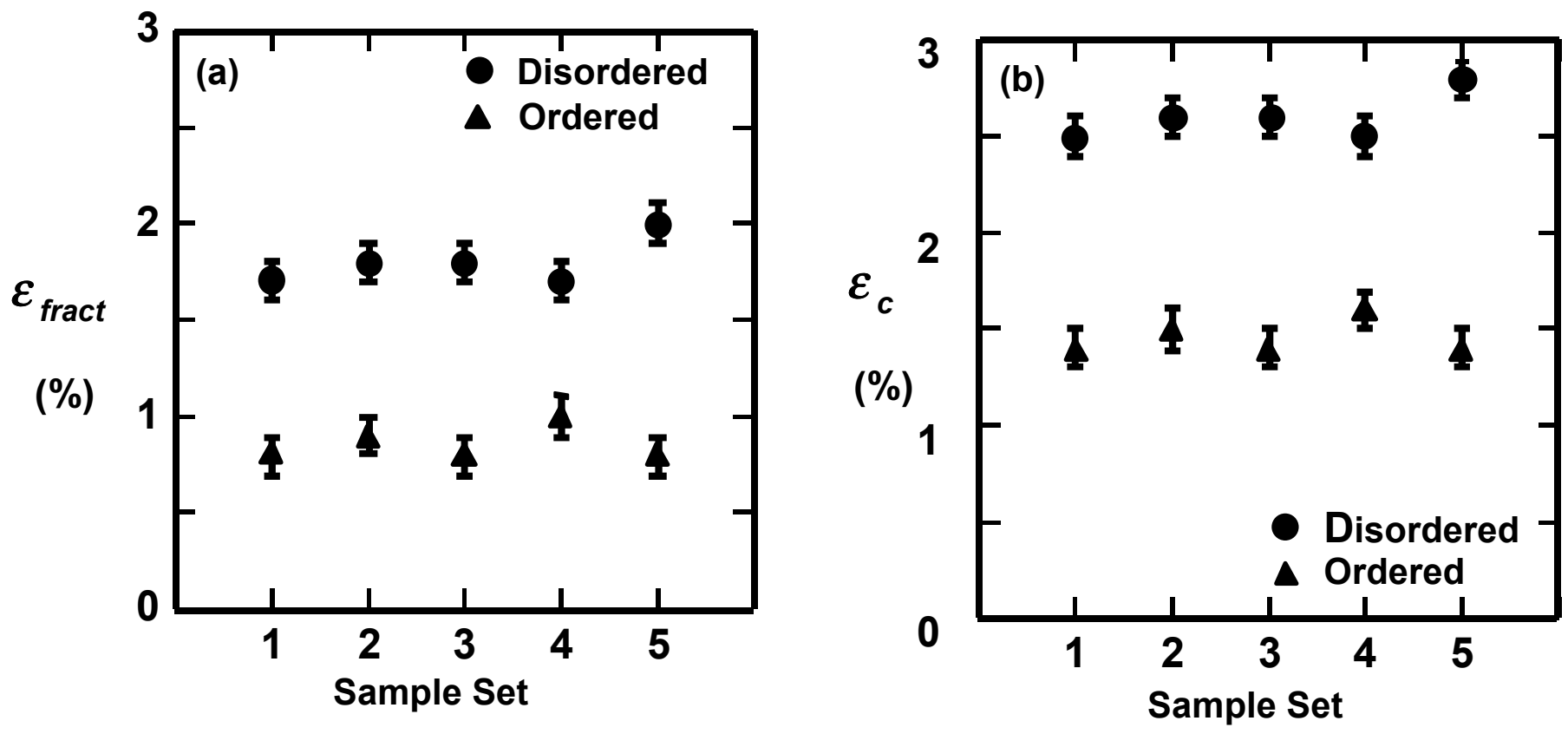

Figure 8. Fracture strain for disordered (circles) and ordered (triangles) $\mathrm{Ni}_{3} \mathrm{Al}$. (a) Applied strain $\varepsilon_{\text {fract }}$. (b) Critical fracture strain from Eq. (2). 

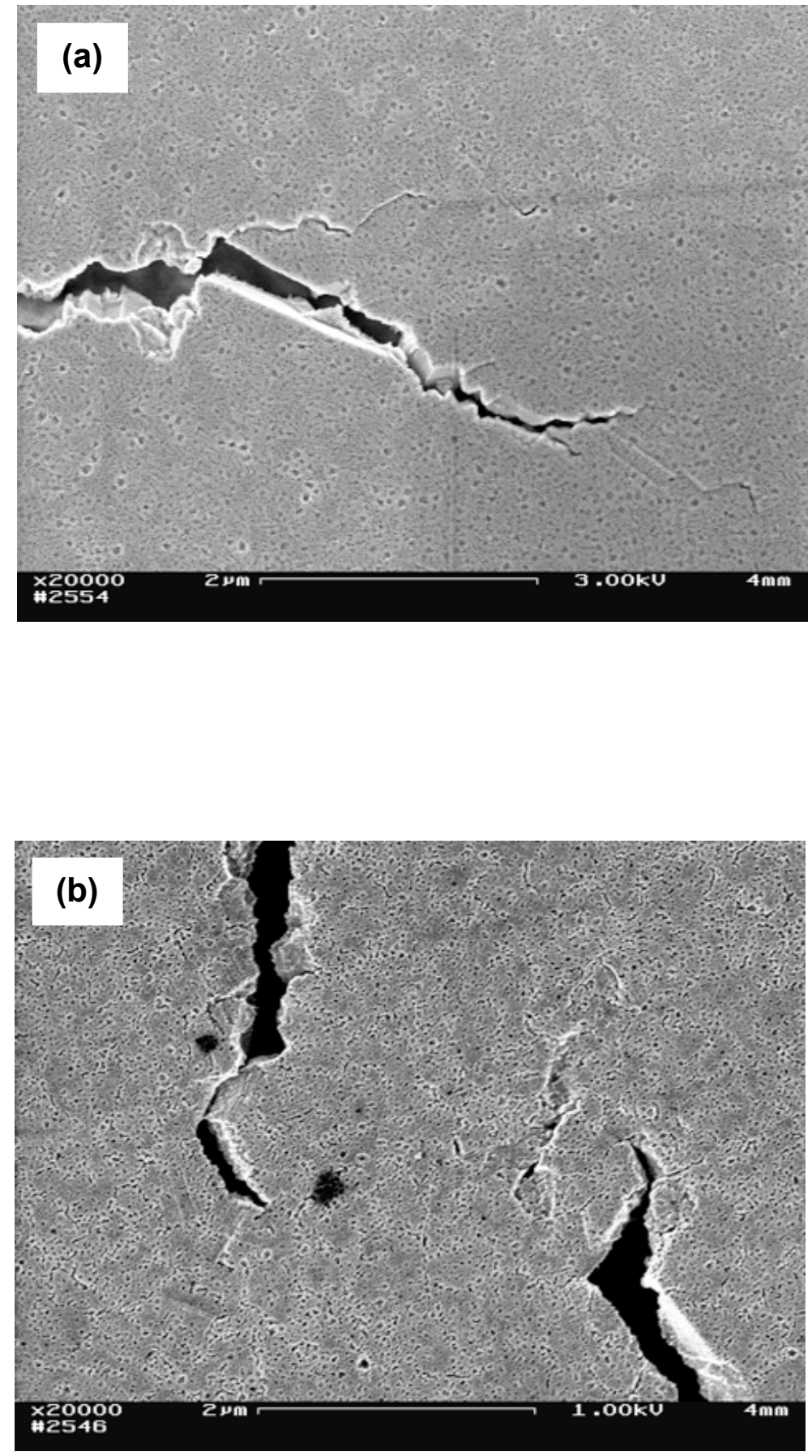

Figure 9. SEM micrograph of the crack tips in the $\mathrm{Ni}_{3} \mathrm{Al}$ thin films. (a) Sharp crack tips in ordered $\mathrm{L}_{2}$ phase. (b) Blunter crack tips in disordered FCC phase. 


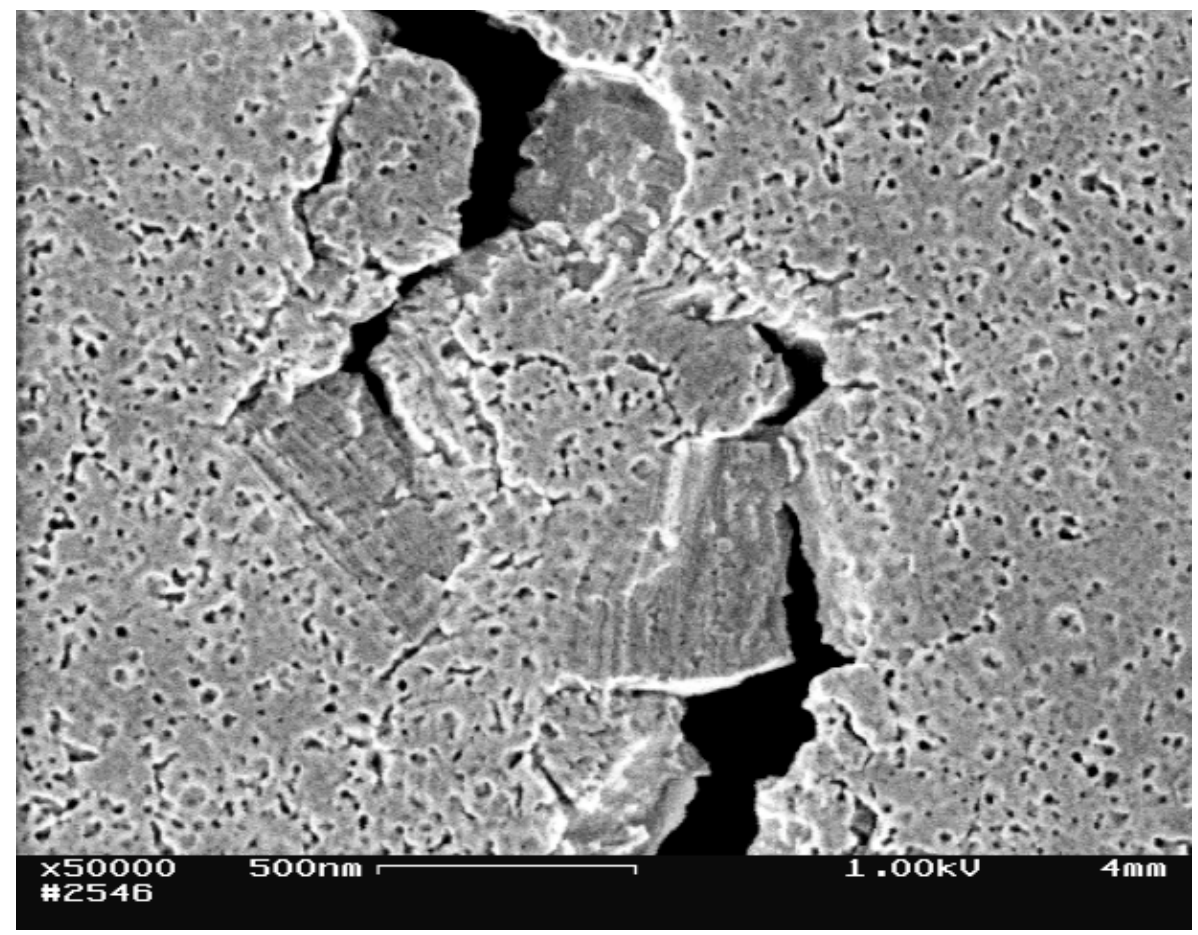

Figure 10. Example of ductile crack bridging, observed only in the disordered FCC phase. 